\title{
Commentary: Quality reporting for salvage cardiac surgery-A deeper dive is needed
}

Erin M. Iannacone, MD, and Leonard N. Girardi, MD

\author{
From the Department of Cardiothoracic Surgery, Weill Cornell Medical College, New York, NY. \\ Disclosures: Authors have nothing to disclose with regard to commercial support. \\ Received for publication Feb 5, 2019; accepted for publication Feb 7, 2019; available ahead of print March 14, \\ 2019. \\ Address for reprints: Leonard N. Girardi, MD, Department of Cardiothoracic Surgery, Weill Cornell Medical Col- \\ lege, S525 E 68th St, M-424, New York, NY 10021 (E-mail: lngirard@ med.cornell.edu). \\ J Thorac Cardiovasc Surg 2020;159:201-2 \\ $0022-5223 / \$ 36.00$ \\ Copyright (C) 2019 by The American Association for Thoracic Surgery \\ https://doi.org/10.1016/j.jtcvs.2019.02.030
}

Public reporting is ubiquitous in today's world. It so permeates our daily activities that it is not questioned, but expected. For better or worse, people make decisions on the basis of a vast array of public information, such as Uber ratings or Yelp reviews of their local restaurants. Physicians are also subject to public opinion of the "service" that they provide, and these influential, but potentially unsubstantiated, evaluations are there for all to view on the World Wide Web.

At some level, sophisticated consumers may be able to comprehend that a significant component of these reports is opinion rather than fact. The interpretation of outcomes in cardiac surgery, however, is a bit more complex than conjecture regarding one's bedside manner. A plus or minus metric such as operative mortality may seem fairly straightforward on the surface. Nonetheless, we all know how such data can be profoundly influenced by preoperative comorbidities, intraoperative events, and postoperative care. Advanced statistical analysis and risk adjustment are mandatory to establish benchmarks of excellent, acceptable, and unacceptable performance. And although the public is entitled to know good from bad, access to and misinterpretation of complicated quality metrics can lead to unintended negative consequences. ${ }^{1}$ One enduring concern is that physicians will be less likely to intervene in treating high-risk patients in the setting of public outcomes reporting. ${ }^{2}$ Concerns that current risk prediction models are inadequate as patients become sicker have proved to be valid. ${ }^{3}$ In this issue of the Journal, Chancellor and colleagues ${ }^{4}$ evaluate the current Society of Thoracic Surgeons (STS) model of risk-adjusted outcomes in the sickest of the sick, those requiring "salvage" cardiac surgery. These results strongly suggest that more detailed stratification of severity of illness and surgical complexity be done before these results are made available to the public.

From 19 centers reporting data to the Virginia Cardiac Services Quality Initiative during a 15-year period, only 117 of the 76,498 cases $(0.15 \%)$ were considered "salvage." The salvage case group had significantly greater observed mortality than that predicted by the STS predicted

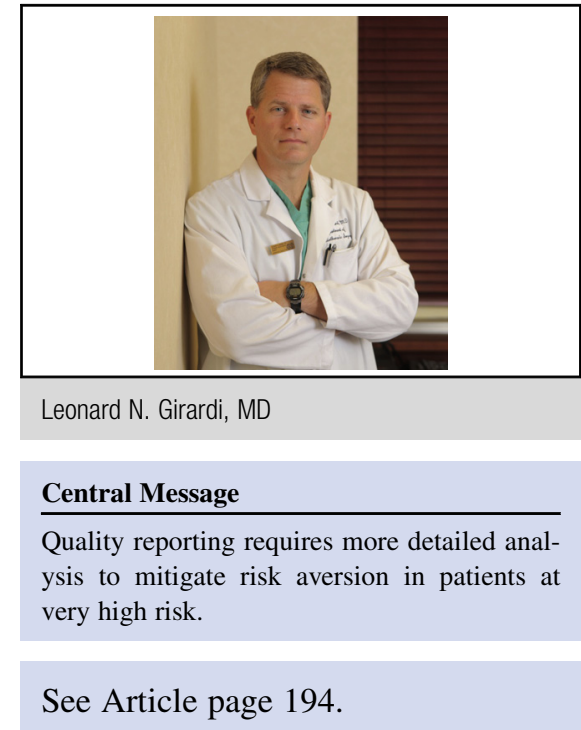

risk of mortality tool. This was far different than the observed mortalities of the elective, urgent, and emergency case group, which were much more accurately predicted by the STS predicted risk of mortality tool. It should be noted that the small number of patients in the salvage cohort, and the high variability in outcomes among these 19 centers, certainly made meaningful statistical analysis quite difficult. Interestingly, $54 \%$ of the patients in the salvage group survived to discharge, a gratifying rate of success that may provide surgeons with hope when facing what may seem to be insurmountable odds. A recent retrospective review may provide additional encouragement. Santarpino and colleagues ${ }^{5}$ examined longer-term outcomes of 85 patients undergoing salvage coronary bypass grafting. They reported a 5 -year survival of $40.9 \%$. Others have found similar results, suggesting that a meaningful recovery may be possible even when patients are being maintained by mechanical circulatory support or ongoing cardiopulmonary resuscitation. ${ }^{6}$

A call for more detailed reporting to our benchmark databases seems completely appropriate and very doable. The intricacies of aortic surgery that are now reported to the STS database make the details of a "salvage" case seem pedestrian by comparison. This level of complexity would permit more accurate adjudication of risk for these rare cases and perhaps assuage concerns that somehow a patient's death in such a circumstance will land one on the front page of The New York Post. The concerns of fiscal responsibility and institutional reputation (briefly mentioned in this 
article) are not germane to the discussion by Chancellor and colleagues ${ }^{4}$ of how inadequate adjustment of publicly reported data affects surgical risk aversion. Improvements in our reporting and analysis, however, should give all proceduralists the additional courage (protection?) necessary to offer potentially lifesaving procedures to a greater number of patients who have no other options.

\section{References}

1. Werner RM, Asch DA. The unintended consequences of publicly reporting quality information. JAMA. 2005;293:1239-44.

2. Waldo SW, McCabe JM, O'Brien C, Kennedy KF, Joynt KE, Yeh RW. Association between public reporting of outcomes with procedural management and mortality for patients with acute myocardial infarction. J Am Coll Cardiol. 2015;65: 1119-26.

3. LaPar D, Filardo G, Crosby IK, Speir AM, Rich JB, Kron IL, et al. The challenge of achieving $1 \%$ operative mortality for coronary artery bypass grafting: a multiinstitution Society of Thoracic Surgeons Database analysis. J Thorac Cardiovasc Surg. 2014;148:2686-96.

4. Chancellor WZ, Mehaffey JH, Beller JP, Krebs ED, Hawkins RB, Yount K, et al. Current quality reporting methods are not adequate for salvage cardiac operations. J Thorac Cardiovasc Surg. 2020;159:194-200.e1.

5. Santarpino G, Ruggieri VG, Mariscalco G, Bounader K, Beghi C, Fischlein T, et al. Outcome in patients having salvage coronary artery bypass grafting. Am J Cardiol. 2015;116:1193-8.

6. Axelsson TA, Mennander A, Malmberg M, Gunn J, Jeppsson A, Gudbjartsson T. Is emergency and salvage coronary artery bypass grafting justified? The Nordic Emergency/Salvage coronary artery bypass grafting study. Eur J Cardiothorac Surg. 2016;49:1451-6. 